\title{
ГЕОГРАФИЯ
}

И ГЕОИНФОРМАТИКА

DOI: https://doi.org/10.15688/nsr.jvolsu.2019.2.6

UDC 502.63

LBC 26.8

\section{DETERMINATION OF THE PYRO-FACTOR ECOLOGICAL SUCCESSIONS DURATION IN THE ZONAL LANDSCAPES OF THE VOLGOGRAD REGION ACCORDING TO THE REMOTE SENSING DATA ${ }^{1}$}

\author{
Stanislav S. Shinkarenko \\ Federal Scientific Centre of Agroecology, Complex Melioration and Protective Afforestation of the Russian \\ Academy of Sciences, Volgograd State University, Volgograd, Russian Federation
}

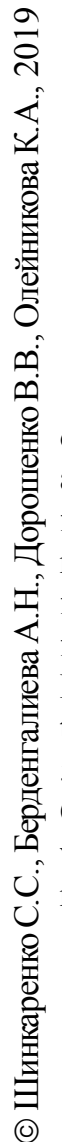

\author{
Asel N. Berdengalieva \\ Volgograd State University, Volgograd, Russian Federation \\ Valeriya V. Doroshenko \\ Volgograd State University, Volgograd, Russian Federation
}

\section{Kseniya A. Oleynikova}

Federal Scientific Centre of Agroecology, Complex Melioration and Protective Afforestation of the Russian Academy of Sciences, Volgograd, Russian Federation

\begin{abstract}
The aim of the work is to determine the spatial characteristics of the distribution of the burnt areas of natural zonal landscapes of the Volgograd region with different duration of pyro-factor successions, taking into account the frequency of fires. Based on the previously developed thematic geo-information layers of the steppe fires in the region using overlay operations, the duration of post-pyrogenic periods in the municipal districts of the region was determined, taking into account the total number of fires from 1998-2018. The largest areas covered by fire have a succession duration of 2-3 years and 12-14 years at the beginning of 2019, which corresponds to the fires of 2016-2017 and 2005-2007, respectively. Large areas after the fires of 2001-2002 are located in Ilovlinsky, Kletsky, Pallasovsky and Surovikinsky districts. The largest area of land covered by fire in 2004-2006 is located in the Danilovsky, Ilovlinsky, Olkhovsky and Pallas districts. In our opinion, landscapes affected by fire no more than 5-7 years ago are suitable for the analysis of pyrogenic shifts. These territories are located in Frolovsky, Chernyshkovsky, Kotovsky, Ilovlinsky, Pallasovsky, Leninsky, Kamyshinsky, Staropoltavsky districts. The results will serve as the basis for field studies and the analysis of the spectral characteristics of overgrowing burns from remote sensing materials.
\end{abstract}

Key words: Volgograd region, landscape fires, satellite monitoring, remote sensing, GIS. 
УДК 502.63

ББК 26.8

\title{
ОПРЕДЕЛЕНИЕ ДЛИТЕЛЬНОСТИ ПИРОГЕННЫХ СУКЦЕССИЙ В ЗОНАЛЬНЫХ ЛАНДШАФТАХ ВОЛГОГРАДСКОЙ ОБЛАСТИ ПО ДАННЫМ ДИСТАНЦИОННОГО ЗОНДИРОВАНИЯ ${ }^{1}$
}

\author{
Станислав Сергеевич Шинкаренко \\ Федеральный научный центр агроэкологии, комплексных мелиораций и защитного лесоразведения Российской \\ академии наук, Волгоградский государственный университет, г. Волгоград, Российская Федерация
}

\section{Асель Нурлановна Берденгалиева}

Волгоградский государственный университет, г. Волгоград, Российская Федерация

Валерия Витальевна Дорошенко

Волгоградский государственный университет, г. Волгоград, Российская Федерация

\section{Ксения Александровна Олейникова}

Федеральный научный центр агроэкологии, комплексных мелиораций и защитного лесоразведения Российской академии наук, г. Волгоград, Российская Федерация

\begin{abstract}
Аннотация. Целью работы является определение пространственных особенностей распределения выгоревших территорий естественных зональных ландшафтов Волгоградской области с различной длительностью пирогенных смен с учетом повторяемости пожаров. На основе разработанных ранее тематических геоинформационных слоев степных пожаров региона с применением оверлейных операций определены продолжительности постпирогенных периодов в муниципальных районах области с учетом общего количество пожаров за 1998-2018 годы. Наибольшие площади пройденных огнем участков имеют длительность сукцессий 2-3 года и 12-14 лет на начало 2019 г., что соответствует пожарам 2016-2017 и 2005-2007 гг. соответственно. Большие площади после пожаров 2001-2002 гг. расположены в Иловлинском, Клетском, Палласовском и Суровикинском районах. Наибольшая доля земель, пройденных огнем в 2004-2006 гг, находится в Даниловском, Иловлинском, Ольховском и Палласовском районах. На наш взгляд, для анализа пирогенных смен подходят ландшафты, затронутые огнем не более 5-7 лет назад. Эти территории расположены во Фроловском, Чернышковском, Котовском, Иловлинском, Палласовском, Ленинском, Камышинском, Старополтавском районах. Полученные результаты послужат основой для полевых исследований и анализа спектральных характеристик зарастающих гарей по материалам дистанционного зондирования.

Ключевые слова: Волгоградская область, ландшафтные пожары, спугниковый мониторинг, дистанционное зондирование, ГИС.
\end{abstract}

Введение. Регулярные пожары могут быть определены как экзогенный локальный фактор, приводящий к нарушениям и трансформации экосистем $[2 ; 5 ; 13]$. Достаточно много исследований посвящено изучению лесных пожаров и динамике состояния лесных экосистем после пожаров, но степные пожары и их масштабы изучены достаточно слабо $[1 ; 10]$. По мнению ряда исследователей, степные пожары способствуют улучшению состояния травяных растительных сообществ, другие, напротив, отмечают деструктивное воздействие степных пожаров на естествен- ные фитоценозы [22; 23; 25]. Установлено, что после летних пожаров в Заволжье растительность не восстанавливается до следующего сезона [11]. Также пожары вызывают гибель членистоногих и грызунов, способствуют развитию эрозионных процессов, иссушению и засолению верхних почвенных горизонтов, снижают подземную фитомассу и запас семян в почве $[8 ; 12 ; 18 ; 19]$.

Данная работа направлена на определение длительностей пирогенных изменений в зональных ландшафтах Волгоградской области. Для анализа пирогенных сукцессионных смен необ- 


\section{ГЕОГРАФИЯ И ГЕОИНФОРМАТИКА}

ходимо объективно определять длительности периодов, которые прошли после пожаров, количество пожаров на исследуемых участках и другие закономерности пожарного режима территории. Как показывает опыт, это возможно только на основе данных дистанционного зондирования $[3 ; 4 ; 6 ; 9 ; 20]$. Причем для анализа пирогенных сукцессий в степных ландшафтах в качестве источников данных подходят только материалы визуального дешифрирования [15; 16].

Объект и методы исследований. Исследование основано на разработанных ранее геоинформационных слоях степных пожаров в Волгоградской области, включающих контура гарей в естественных зональных ландшафтах за 1998-2018 гг,, определенных на основе визуального дешифрирования, а также архивов данных об активных очагах горения и выгоревших площадях [21;24]. Всего проанализировано 3776 объектов общей площадью более 50 тыс. км ${ }^{2}$, в том числе слой повторяемости пожаров [7; 14]. В программе QGIS версий 2.18 и 3.2 на основе оверлейных операций пересечения и разницы слоев с выгоревшими площадями за разные годы определены полигоны с разной длительностью пирогенных сукцессий и количеством пожаров, в том числе в разрезе муниципальных районов.

Результаты исследования. На рисунке 1 показаны пространственно-временные

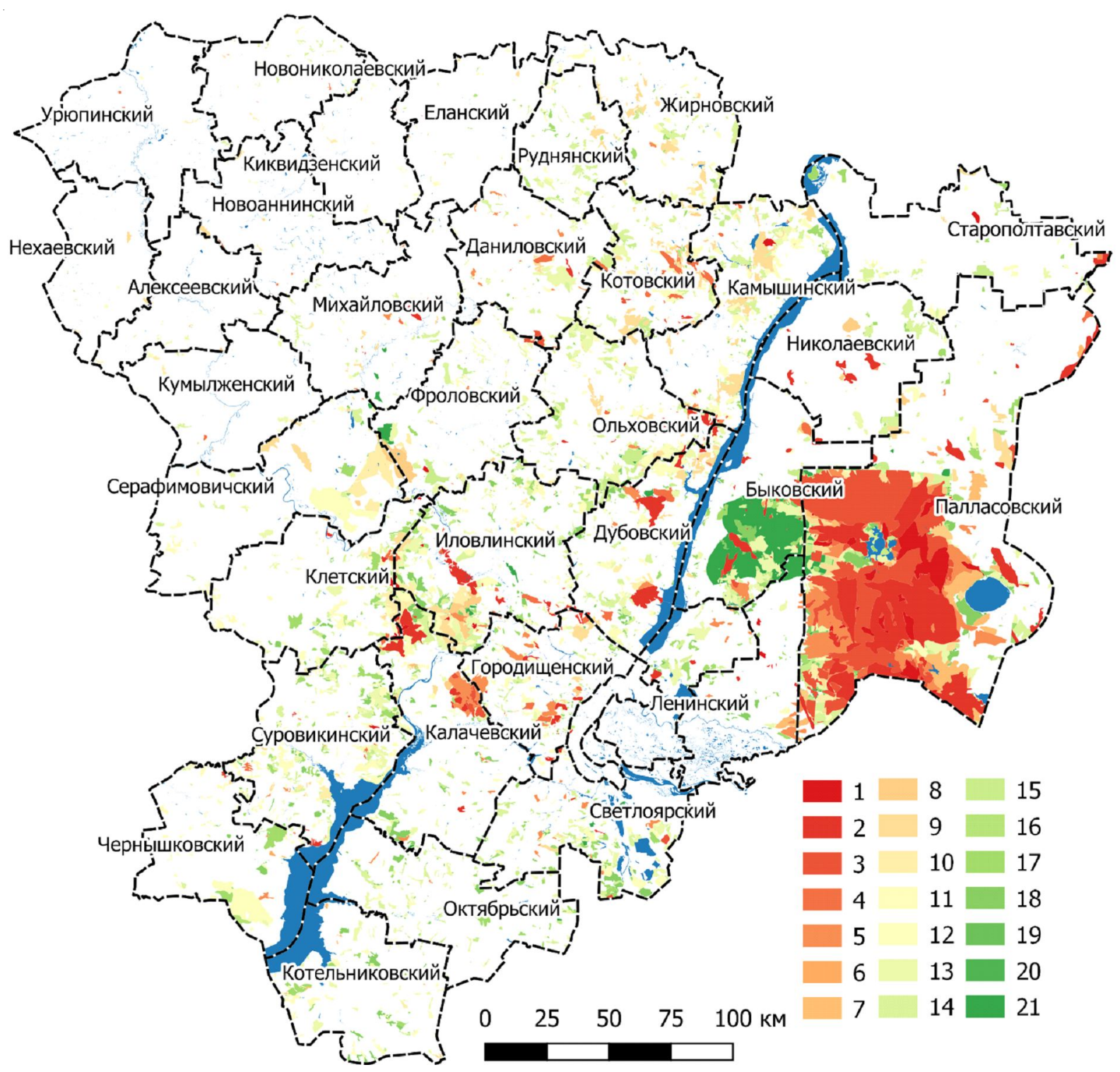

Рис. 1. Длительности пирогенных сукцессий (в годах) в зональных ландшафтах Волгоградской области на начало 2019 г. 
аспекты распределения территорий с различной длительностью пирогенных сукцессий. Общая площадь затронутых огнем зональных ландшафтов в регионе составляет около 20 тыс. км ${ }^{2}$ [14]. Наибольшие площади из пройденных огнем участков имеют длительность сукцессий 2-3 года и 12-14 лет на начало 2019 г. (табл. 1), что соответствует пожарам 2016-2017 и 2005-2007 гг. соответственно.

С точки зрения распределения по районам области большая часть исследуемых площадей расположена в Палласовском районе, что связано с особенностями пожарного режима территории: большая часть степных пожаров приходится именно на этот район [17]. Большие подходящие для исследований площади расположены еще в Быковском, Дубовском, Иловлинском, Калачевском, Камышинском, Клетском, Серафимовичском, Суровикинском и Чернышковском районах.

Для анализа закономерностей пирогенных изменений в ландшафтах нужно знать не только длительность сукцессий после пожаров разных лет, но и количество пожаров на исследуемой территории, поскольку повторные палы могут существенно менять структуру фитоценозов. Также необходимо отбирать территории с достаточной продолжительностью постпирогенного периода. Пересечением полигонов с количеством пожаров в атрибутах получен слой с длительностью сукцессии, годом последнего пожара и общим количеством пожаров в атрибутивной таблице. На рисунке 2 показано распределение участков, пройденных огнем только один раз за исследуемый период и соответствующий год пожара. Практически половина всех представленных территорий выгорела в 2004-2008 гг., среди остальных пятилеток изучаемого пери- ода площади распределены относительно равномерно.

Наибольшая установленная длительность пирогенных сукцессий - 21 год после пожаров 1998 г., большая часть этих земель (73\%) находится в Быковском районе. Большие площади после пожаров 2001-2002 гг. расположены в Иловлинском, Клетском, Палласовском и Суровикинском районах. Наибольшая доля земель, пройденных огнем в 20042006 гг., находится в Даниловском, Иловлинском, Ольховском и Палласовском районах. Пожары на очень больших площадях были в 2010 г., большая доля земель, восстанавливающихся после этого года, расположена в Камышинском, Котовском и Палласовском районах. После 2010 г. практически все площади сосредоточены в Палласовском районе, исключение составляют пожары 2017 г. в Дубовском районе.

Представляет интерес вклад пожаров отдельных лет в общую повторяемость степных пожаров в регионе (см. табл. 2). Структурировав эти данные, можно не только проанализировать влияние длительности сукцессии на состояние фитоценоза, но и определить роль повторяемости пожаров в пирогенных сменах растительности. Наибольшие площади, пройденные огнем только от одного до пяти раз, выгорели в 1998, 2002, 2005-2007, 2010 годах.

На территориях с максимальным количеством пожаров (11-13) наибольший вклад оказали пожары первого десятилетия XXI века, а также крупные пожары 2012, 2014 и 2016 гг. в Палласовском районе. После 2010 г. пожары в большей части происходили на тех же участках, что и в первом десятилетии, из-за чего величины площадей, единожды пройденных огнем, снижаются.

\section{Площади территорий Волгоградской области с разной длительностью}

Таблица 1 пирогенных сукцессий без учета повторяемости пожаров

\begin{tabular}{|l|c|c|c|c|c|c|c|}
\hline Длительность, лет & 1 & 2 & 3 & 4 & 5 & 6 & 7 \\
\hline Площадь, тыс. га & 50,8 & 260,3 & 212,3 & 36,3 & 117,0 & 1,2 & 46,6 \\
\hline Длительность, лет & 8 & 9 & 10 & 11 & 12 & 13 & 14 \\
\hline Площадь, тыс. га & 31,3 & 141,7 & 54,6 & 110,6 & 160,4 & 203,5 & 198,3 \\
\hline Длительность, лет & 15 & 16 & 17 & 18 & 19 & 20 & 21 \\
\hline Площадь, тыс. га & 59,1 & 4,8 & 117,1 & 84,9 & 0,3 & 0,0 & 97,7 \\
\hline
\end{tabular}




\section{ГЕОГРАФИЯ И ГЕОИНФОРМАТИКА}

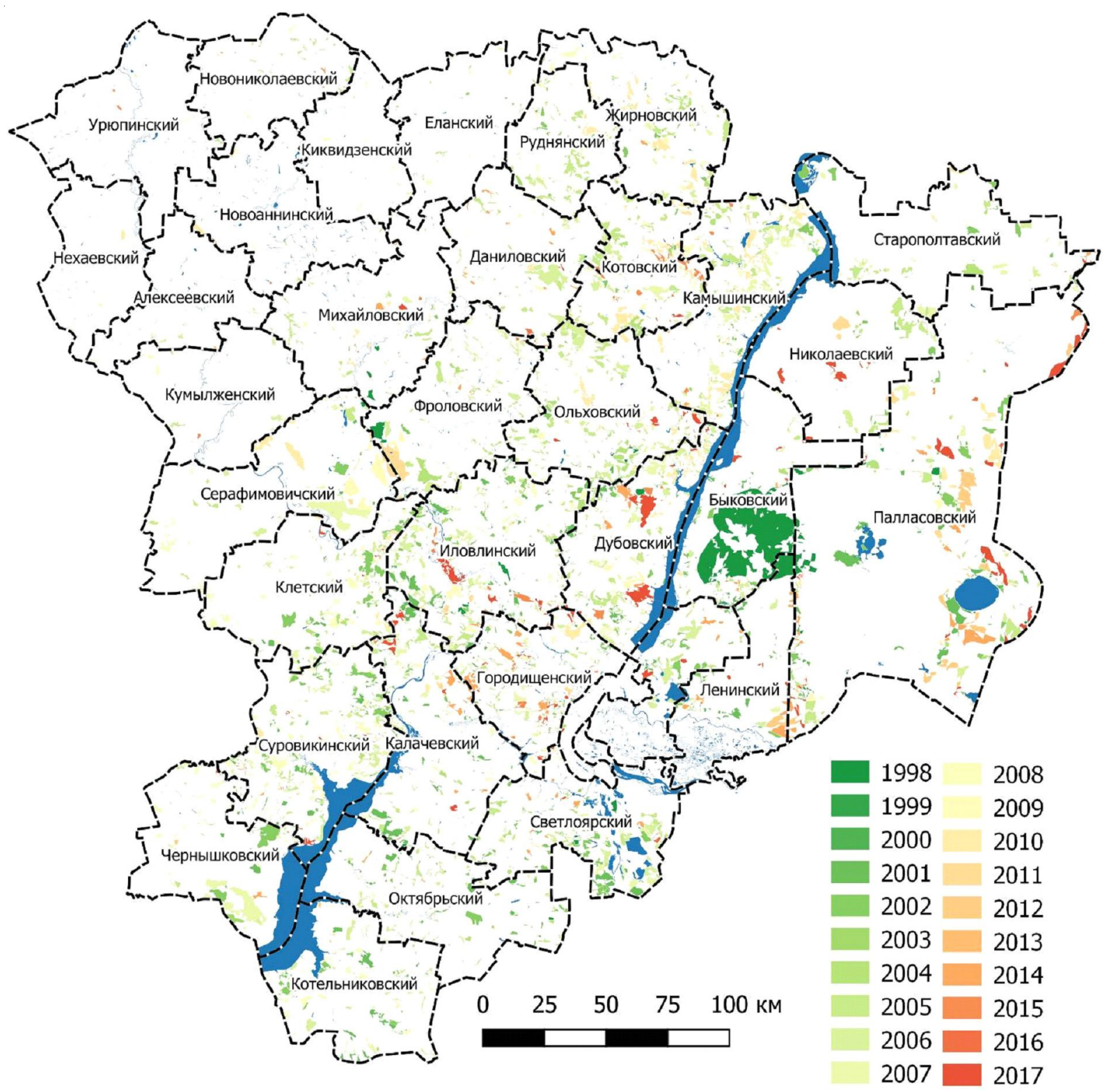

Рис. 2. Участки на территории Волгоградской области, пройденные огнем только один раз в 1998-2017 гг.

В таблице 3 показаны площади территорий с различной длительностью постпирогенного периода с учетом повторяемостей пожаров. Эти данные послужат основой для полевых геоботанических исследований и анализа спектральных характеристик зарастающих гарей по материалам дистанционного зондирования, для определения закономерностей пирогенных смен и соответствующих изменений спектрального отклика.

Заключение. Работа была направлена на определение выгоревших территорий с разной длительностью пирогенных смен, подходящих для изучения растительных смен пос- ле пожаров. Для этого кроме собственно продолжительности постпирогенного периода необходимо определение повторяемости пожаров, так как повторные пожары могут существенно изменять продуктивность и флористический состав фитоценозов. В результате исследований определены территории пройденные огнем от 1 до 13 раз за 1998-2018 гг. с учетом повторяемости пожаров. Наибольшие площади пройденных огнем участков имеют длительность сукцессий 2-3 года и 12-14 лет на начало 2019 г., что соответствует пожарам 2016-2017 и 2005-2007 гг. соответственно. Большие площади после пожаров 2001- 
2002 гг. расположены в Иловлинском, Клетском, Палласовском и Суровикинском районах. Наибольшая доля земель, пройденных огнем в 2004-2006 гг., находится в Даниловском, Иловлинском, Ольховском и Палласовском районах. На наш взгляд, для анализа пироген-

Таблица 2

Вклад пожаров разных лет в повторяемость степных пожаров

\begin{tabular}{|c|c|c|c|c|c|c|c|c|c|c|c|c|c|}
\hline \multirow{3}{*}{ Год } & \multicolumn{13}{|c|}{ Площади участков, тыс. га } \\
\hline & \multicolumn{13}{|c|}{ Количество пожаров в 1998-2018 гг. } \\
\hline & 1 & 2 & 3 & 4 & 5 & 6 & 7 & 8 & 9 & 10 & 11 & 12 & 13 \\
\hline 1998 & 97,7 & 45,6 & 32,4 & 26,6 & 23,6 & 22,3 & 27,4 & 44,5 & 50,8 & 54,8 & 26,1 & 4,8 & 0,4 \\
\hline 1999 & 0,0 & 0,1 & 0,3 & 0,0 & 0,0 & 0,0 & 0,1 & 0,2 & 0,5 & 0,3 & 0,0 & 0,0 & 0,0 \\
\hline 2000 & 0,3 & 1,3 & 0,5 & 0,3 & 0,7 & 0,4 & 0,0 & 0,0 & 0,0 & 0,0 & 0,0 & 0,0 & 0,0 \\
\hline 2001 & 74,7 & 74,0 & 62,9 & 53,8 & 42,5 & 40,6 & 43,3 & 60,9 & 72,5 & 69,7 & 30,6 & 4,9 & 0,4 \\
\hline 2002 & 108,5 & 54,1 & 22,8 & 15,7 & 14,7 & 17,9 & 21,8 & 37,6 & 53,3 & 59,8 & 26,8 & 4,5 & 0,4 \\
\hline 2003 & 4,4 & 2,8 & 1,6 & 1,4 & 1,9 & 1,9 & 1,9 & 3,2 & 1,9 & 1,1 & 0,7 & 0,1 & 0,0 \\
\hline 2004 & 41,9 & 29,5 & 22,0 & 19,6 & 16,4 & 15,0 & 19,8 & 32,3 & 48,6 & 53,1 & 29,1 & 4,9 & 0,4 \\
\hline 2005 & 162,2 & 87,8 & 32,3 & 23,3 & 19,9 & 26,8 & 29,5 & 41,8 & 52,2 & 57,2 & 28,6 & 4,9 & 0,4 \\
\hline 2006 & 137,0 & 77,2 & 48,7 & 36,4 & 24,0 & 21,0 & 19,0 & 30,2 & 36,0 & 43,9 & 16,0 & 3,0 & 0,3 \\
\hline 2007 & 108,2 & 56,0 & 20,5 & 13,8 & 6,9 & 6,8 & 5,1 & 12,3 & 18,8 & 17,9 & 13,6 & 2,9 & 0,3 \\
\hline 2008 & 71,1 & 34,4 & 13,6 & 10,1 & 11,7 & 12,1 & 13,2 & 13,9 & 16,3 & 16,5 & 7,9 & 1,5 & 0,1 \\
\hline 2009 & 26,5 & 19,1 & 7,9 & 7,0 & 7,0 & 7,5 & 10,7 & 24,4 & 40,0 & 42,3 & 14,7 & 2,5 & 0,2 \\
\hline 2010 & 83,8 & 37,9 & 18,1 & 17,8 & 21,0 & 21,8 & 28,4 & 42,2 & 55,4 & 53,8 & 24,3 & 4,0 & 0,4 \\
\hline 2011 & 19,0 & 6,8 & 9,6 & 6,1 & 2,9 & 5,1 & 6,5 & 11,6 & 14,0 & 12,3 & 6,8 & 1,6 & 0,1 \\
\hline 2012 & 19,3 & 16,1 & 19,0 & 19,0 & 16,3 & 14,6 & 21,1 & 29,2 & 45,3 & 50,4 & 25,9 & 4,5 & 0,4 \\
\hline 2013 & 0,7 & 0,3 & 0,5 & 0,4 & 0,2 & 0,1 & 0,0 & 0,0 & 0,0 & 0,0 & 0,0 & 0,0 & 0,0 \\
\hline 2014 & 40,9 & 22,1 & 19,7 & 21,6 & 24,4 & 28,3 & 31,6 & 48,3 & 60,5 & 63,1 & 29,2 & 4,9 & 0,4 \\
\hline 2015 & 17,4 & 9,9 & 4,8 & 2,8 & 1,9 & 0,9 & 1,4 & 1,6 & 2,6 & 3,1 & 1,6 & 0,2 & 0,1 \\
\hline 2016 & 3,6 & 9,5 & 14,0 & 19,9 & 20,8 & 22,6 & 27,1 & 46,0 & 62,8 & 64,6 & 27,5 & 4,9 & 0,4 \\
\hline 2017 & 52,7 & 35,0 & 16,6 & 19,8 & 13,1 & 10,8 & 14,2 & 18,7 & 25,4 & 32,0 & 21,7 & 3,5 & 0,3 \\
\hline 2018 & 3,2 & 2,5 & 1,8 & 1,8 & 1,8 & 2,6 & 5,1 & 7,6 & 7,9 & 9,3 & 5,4 & 1,6 & 0,1 \\
\hline
\end{tabular}

Таблица 3

Длительности пирогенных сукцессий на участках с разным количеством пожаров

\begin{tabular}{|c|c|c|c|c|c|c|c|c|c|c|c|c|}
\hline \multirow{3}{*}{ Длительность } & \multicolumn{12}{|c|}{ Площади участков, тыс. га } \\
\hline & \multicolumn{12}{|c|}{ Количество пожаров в 1998-2018 гг. } \\
\hline & 1 & 2 & 3 & 4 & 5 & 6 & 7 & 8 & 9 & 10 & 11 & 12 \\
\hline 1 & 3,2 & 2,5 & 1,8 & 1,8 & 1,8 & 2,6 & 5,1 & 7,6 & 7,9 & 9,3 & 5,3 & 1,6 \\
\hline 2 & 52,5 & 34,9 & 16,3 & 19,7 & 13,1 & 10,8 & 14,1 & 18,5 & 24,6 & 30,5 & 20,8 & 3,2 \\
\hline 3 & 3,6 & 9,5 & 13,5 & 19,1 & 18,8 & 19,9 & 20,0 & 33,0 & 39,5 & 30,6 & 4,4 & 0,2 \\
\hline 4 & 17,2 & 9,0 & 4,7 & 2,2 & 0,7 & 0,5 & 0,4 & 0,4 & 0,7 & 0,1 & 0,0 & 0,0 \\
\hline 5 & 40,5 & 18,0 & 14,4 & 11,3 & 11,5 & 10,4 & 6,1 & 2,8 & 1,2 & 0,0 & 0,0 & 0,0 \\
\hline 6 & 0,7 & 0,1 & 0,1 & 0,2 & 0,0 & 0,0 & 0,0 & 0,0 & 0,0 & 0,0 & 0,0 & 0,0 \\
\hline 7 & 19,2 & 9,4 & 10,7 & 3,1 & 1,7 & 0,6 & 0,5 & 1,0 & 0,0 & 0,0 & 0,0 & $\overline{0,0}$ \\
\hline 8 & 18,9 & 4,3 & 6,0 & 2,0 & 0,0 & 0,0 & 0,0 & 0,0 & 0,0 & 0,0 & 0,0 & 0,0 \\
\hline 9 & 83,1 & 34,0 & 10,2 & 7,1 & 4,1 & 0,8 & 0,4 & 0,0 & 0,0 & 0,0 & 0,0 & 0,0 \\
\hline 10 & 26,3 & 15,7 & 6,2 & 3,7 & 1,3 & 0,8 & 0,0 & 0,0 & 0,0 & 0,0 & 0,0 & 0,0 \\
\hline 11 & 70,3 & 28,1 & 6,6 & 2,9 & 0,1 & 0,0 & 0,0 & 0,0 & 0,0 & 0,0 & 0,0 & 0,0 \\
\hline 12 & 107,0 & 37,2 & 10,5 & 2,7 & 0,6 & 0,0 & 0,0 & 0,0 & 0,0 & 0,0 & 0,0 & 0,0 \\
\hline 13 & 135,1 & 44,1 & 17,2 & 2,8 & 0,6 & 0,2 & 0,0 & 0,0 & 0,0 & 0,0 & 0,0 & 0,0 \\
\hline 14 & 159,0 & 32,1 & 2,1 & 0,4 & 0,0 & 0,0 & 0,0 & 0,0 & 0,0 & 0,0 & 0,0 & 0,0 \\
\hline 15 & 41,0 & 14,3 & 2,6 & 0,2 & 0,0 & 0,0 & 0,0 & 0,0 & 0,0 & 0,0 & 0,0 & 0,0 \\
\hline 16 & 4,3 & 0,4 & 0,0 & 0,0 & 0,0 & 0,0 & 0,0 & 0,0 & 0,0 & 0,0 & 0,0 & 0,0 \\
\hline 17 & 106,4 & 8,0 & 0,3 & 0,0 & 0,0 & 0,0 & 0,0 & 0,0 & 0,0 & 0,0 & 0,0 & 0,0 \\
\hline 18 & 72,7 & 10,3 & 0,2 & 0,0 & 0,0 & 0,0 & 0,0 & 0,0 & 0,0 & 0,0 & 0,0 & 0,0 \\
\hline 19 & 0,2 & 0,0 & 0,0 & 0,0 & 0,0 & 0,0 & 0,0 & 0,0 & 0,0 & 0,0 & 0,0 & 0,0 \\
\hline 20 & 0,0 & 0,0 & 0,0 & 0,0 & 0,0 & 0,0 & 0,0 & 0,0 & 0,0 & 0,0 & 0,0 & 0,0 \\
\hline 21 & 96,7 & 0,7 & 0,0 & 0,0 & 0,0 & 0,0 & 0,0 & 0,0 & 0,0 & 0,0 & 0,0 & 0,0 \\
\hline
\end{tabular}


ных смен подходят ландшафты, затронутые огнем не более 5-7 лет назад. Эти территории расположены во Фроловском, Чернышковском, Котовском, Иловлинском, Палласовском, Ленинском, Камышинском, Старополтавском районах. Полученные результаты послужат основой для полевых исследований и анализа спектральных характеристик зарастающих гарей по материалам дистанционного зондирования.

\section{ПРИМЕЧАНИЕ}

${ }^{1}$ Работа выполнена при поддержке гранта Президента Российской Федерации № МК-321.2019.5.

\section{СПИСОК ЛИТЕРАТУРЫ}

1. Архипкин, О. П. Пятилетний опыт оперативного космического мониторинга пожаров в Казахстане / О. П. Архипкин, Л. Ф. Спивак, Г. Н. Сагатдинова // Современные проблемы дистанционного зондирования Земли из космоса. - 2007. - Т. 1, № 4. - С. 103-110.

2. Бананова, В. А. К вопросу изучения влияния пожаров на растительность Европейской полупустыни / В. А. Бананова, В. Г. Лазарева // Вестник Калмыцкого университета. - 2007. - № 3. C. 98-102.

3. Барталев, С. А. Методология мониторинга и прогнозирования пирогенной гибели лесов на основе данных спутниковых наблюдений / С. А. Барталев, Ф. В. Стыценко, С. А. Хвостиков // Современные проблемы дистанционного зондирования Земли из космоса. - 2017. - Т. 14, № 6. C. 176-193.

4. Дубинин, М. Ю. Оценка современной динамики пожаров в аридных экосистемах по материалам космической съемки (на примере Черных земель) / М. Ю. Дубинин, А. А. Лущекина, Ф. К. Раделоф // Аридные экосистемы. - 2010. - Т. 6, № 3. C. 5-16.

5. Ильина, В. Н. Пирогенное воздействие на растительный покров / В. Н. Ильина // Самарская Лука: проблемы региональной и глобальной экологии. - 2011. - Т. 20, № 2. - С. 4-30.

6. Лупян, Е. А. Спутниковый мониторинг лесных пожаров в 21 веке на территории Российской Федерации (цифры и факты по данным детектирования активного горения) / Е. А. Лупян, С. А. Барталев, И. В. Балашов // Современные проблемы дистанционного зондирования Земли из космоса. 2017. - T. 14, № 6. - С. 158-175.
7. Мониторинг ландшафтных пожаров в Волгоградской области по данным очагов активного горения / С. С. Шинкаренко [и др.] // Природные системы и ресурсы. - 2018. - Т. 8, № 3. -С. 59-66. DOI: 10.15688/nsr.jvolsu.2018.3.7.

8. Опарин, М. Л. Влияние палов на динамику степной растительности / М. Л. Опарин, О. С. Опарина // Поволжский экологический журнал. - 2003. № 2. - С. 158-171.

9. Оценка площади пожаров на основе комплексирования спутниковых данных различного пространственного разрешения MODIS и Landsat-TM/ ETM+ / С. А. Барталев [и др.] // Современные проблемы дистанционного зондирования Земли из космоса. - 2012. - Т. 9, № 2. - С. 9-26.

10. Павлейчик, В. М. Многолетняя динамика природных пожаров в степных регионах (на примере Оренбургской области) / В. М. Павлейчик // Вестник Оренбургского государственного университета. - 2016. - № 6 (194). - С. 74-80.

11. Рулев, А. С. Анализ сезонной динамики NDVI естественной растительности Заволжья Волгоградской области / А. С. Рулев, С. Н. Канищев, С. С. Шинкаренко // Современные проблемы дистанционного зондирования Земли из космоса. 2016. - Т. 13, № 4. - С. 113-123.

12. Рябинина, Н. О. Современное состояние и динамика степных геосистем юго-востока Русской равнины (на примере природных парков Волгоградской области) / Н. О. Рябинина, С. Н. Канищев, С. С. Шинкаренко // Юг России: экология, и развитие. - 2018. - № 1. - С. 116-127.

13. Скользнева, Л. Н. Влияние пирогенного фактора на растительность Морозовой горы / Л. Н. Скользнева, Т. В. Недосекина // Флора и растительность Центрального Черноземья - 2013 : материалы межрегион. науч. конф. - Курск, 2013. - С. 141-146.

14. Шинкаренко, С. С. Анализ многолетней динамики степных пожаров в Волгоградской области / С. С. Шинкаренко, А. Н. Берденглаивева // Современные проблемы дистанционного зондирования Земли из космоса. - 2019. - Т. 16, № 2. - С. 98-110.

15. Шинкаренко, С. С. Идентификация степных пожаров по данным Landsat и MODIS / C. С. Шинкаренко // Научно-агрономический журнал. 2017. - № 2. - С. 32-34.

16. Шинкаренко, С. С. Оценка динамики площадей степных пожаров в Астраханской области / С. С. Шинкаренко // Современные проблемы дистанционного зондирования Земли из космоса. 2018. - T. 15, № 1. - C. 138-146.

17. Шинкаренко, С. С. Пространственно-временной анализ степных пожаров в Приэльтонье на основе данных Д33 / С. С. Шинкаренко // Вестник Волгоградского государственного университета. Серия 11: Естественные науки. - 2015. - № 1. - 
C. 87-94. - DOI: http://dx.doi.org/10.15688/ jvolsu11.2015.1.9.

18. Cheney, N. The influence of fuel, weather and fire shape variables on fire spread in grasslands / N. P. Cheney, J. S. Gould, W. R. Catchpole // International Journal of Wildland Fire. - 1993. Vol. 3 ( 1). - P. 31-44.

19. Cheney, P. Grassfires: Fuel, weather and fire behaviour / P. Cheney, A. Sullivan. - [S. 1.] : CSIRO Publishing, 2008. $-150 \mathrm{p}$.

20. Dunkan, R. S. Forest Succession and Distance from Forest Edge in an Afro-Tropical Grassland / R. S. Dunkan, V. E. Dunkan // Biotropica. Vol. 32 (1). - 2000. - P. 33-41

21. Giglio, L. The collection 6 MODIS active fire detection algorithm and fire products / L. Giglio, W. Schroeder, C. O. Justice // Remote Sensing of Environment. -2016. - Vol. 178. - P. 31-41.

22. McArthur, A. G. Grassland fire danger meter MkV / A. G. McArthur // CSIRO Division of Forest Annual Report. - 1976-1977. -58 p.

23. Morvan, D. Numerical Study of the Interaction between a Head Fire and a Backfire Propagating in Grassland / D. Morvan, S. Meradji, W. Mell // Fire safety Science-proceedings of the tenth international symposium. - 2011. - P. 1415-1424.

24. Schroeder, W. The New VIIRS $375 \mathrm{~m}$ active fire detection data product: algorithm description and initial assessment / W. Schroeder, P. Oliva, L. Giglio // Remote Sensing of Environment. - 2014. - № 143. P. 85-96.

25. Wooster, M. J. Fire radiative energy for quantitative study of biomass burning: Derivation from the BIRD experimental satellite and comparison to MODIS fire products / M. J. Wooster, B. Zhukov, D. Oertel // Remote Sensing of Environment. - 2003.№ 86.1. - P. 83-107.

\section{REFERENCES}

1. Arkhipkin O.P., Spivak L.F., Sagatdinova G.N. Pyatiletniy opyt operativnogo kosmicheskogo monitoringa pozharov v Kazakhstane [Five-Year Experience of Operational Space Monitoring of Fires in Kazakhstan]. Sovremennye problemy distantsionnogo zondirovaniya Zemli iz kosmosa [Current Problems in Remote Sensing of the Earth from Space], 2007, vol.1. no. 4, pp. 103-110.

2. Bananova V.A., Lazareva V.G. K voprosu izucheniya vliyaniya pozharov na rastitelnost Evropeyskoy polupustyni [To the Question of Studying the Effect of Fires on the Vegetation of the European Semi-Desert]. Vestnik Kalmyckogo universiteta [Bulletin of the Kalmyk University], 2007, no. 3, pp. 98-102.
3. Bartalev S.A., Stytsenko F.V., Khvostikov S.A. Metodologiya monitoringa i prognozirovaniya pirogennoy gibeli lesov na osnove dannykh sputnikovykh nablyudeniy [Methodology of Post-Fire Tree Mortality Monitoring and Prediction Using Remote Sensing Data]. Sovremennye Problemy distantsionnogo zondirovaniya Zemli iz kosmosa [Current Problems in Remote Sensing of the Earth from Space], 2017, vol. 14, no. 6, pp. 176-193.

4. Dubinin M.Yu., Lushchekina A.A., Radelof F.K. Otsenka sovremennoy dinamiki pozharov $\mathrm{v}$ aridnykh ekosistemakh po materialam kosmicheskoy syemki (na primere Chernykh zemel) [Assessment of Modern Burning Dynamics in Arid Ecosystems Using Remote Sensing Data (Case Study of Chernye Zemli)]. Aridnye Ekosistemy [Arid Ecosystems], 2010, vol. 6, no. 3, pp. 5-16.

5. Ilyina V.N. Pirogennoe vozdeystvie na rastitelnyy pokrov [Impact of Fires on the Vegetation Cover]. Samarskaya Luka: problemy regionalnoy $i$ globalnoy ekologii [Samara Luka: Problems of Regional and Global Ecology], 2011, vol. 20, no. 2, pp. 4-30.

6. Lupyan E.A., Bartalev S.A., Balashov I.V. Sputnikovyy monitoring lesnykh pozharov v 21 veke na territorii Rossiiskoy Federatsii (tsifry i fakty po dannym detektirovaniya aktivnogo goreniya) [Satellite Monitoring of Forest Fires in the $21^{\text {st }}$ Century in the Territoryof the Russian Federation (Facts and Figures Based on Active Fires Detection)]. Sovremennye problemy distantsionnogo zondirovaniya Zemli iz kosmosa [Current problems in Remote Sensing of the Earth from Space], 2017, vol. 14, no. 6, pp. 158-175.

7. Shinkarenko S.S., et al. Monitoring landshaftnykh pozharov v Volgogradskoy oblasti po dannym ochagov aktivnogo goreniya [Landscape Fires Monitoring in Volgograd Region According to Active Fire Data]. Prirodnye sistemy $i$ resursy [Natural Systems and Resources], 2018, vol. 8, no. 3, pp. 59-66. DOI: $10.15688 /$ nsr.jvolsu.2018.3.7.

8. Oparin M.L., Oparina O.S. Vliyanie palov na dinamiku stepnoy rastitelnosti [Influence of Fires on Dynamics of Steppe Vegetation]. Povolzhskiy ekologicheskiy zhurnal [Povolzhskiy Journal of Ecology], 2003, no. 2, pp. 158-171.

9. Bartalev S.A.,et al. Otsenka ploshchadi pozharov na osnove kompleksirovaniya sputnikovykh dannykh razlichnogo prostranstvennogo razresheniya MODIS i Landsat-TM/ETM+ [Integrated Burnt Area Assesment Based on Combine Use of MultiResolution MODIS and Landsat-TM/ETM+ Satellite Data]. Sovremennye problemy distantsionnogo zondirovaniya Zemli iz kosmosa [Current Poblems in Remote Sensing of the Earth from Space], 2012, vol. 9, no. 2, pp. 9-26.

10. Pavleychik V.M. Mnogoletnyaya dinamika prirodnykh pozharov v stepnykh regionakh (na primere 
Orenburgskoy oblasti) [Multi-Year Dynamics of Natural Fire in the Steppe Regions On the Example of the Orenburg Region)]. Vestnik Orenburgskogo gosudarstvennogo universiteta [Bulletin of Orenburg State University], 2016, no. 6(194), pp. 74-80.

11. RulevA.S., Kanishchev S.N., Shinkarenko S.S. Analiz sezonnoy dinamiki NDVI estestvennoy rastitelnosti Zavolzhya Volgogradskoy oblasti [Analysis of NDVI Seasonal Dynamics of Natural Vegetation of Low Trans-Volga in Volgograd region]. Sovremennye problemy distantsionnogo zondirovaniya Zemli iz kosmosa [Current Problems in Remote Sensing of the Earth from Space], 2016, vol. 13, no. 4, pp. 113-123.

12. Ryabinina N.O., Kanishchev S.N., Shinkarenko S.S. Sovremennoe sostoyanie i dinamika stepnykh geosistem yugo-vostoka Russkoy ravniny (na primere prirodnykh parkov Volgogradskoy oblasti) [The Current State and Dynamics of Geosystems in the South-East of the Russian Plain (by the Example of the Natural Parks in Volgograd Region)]. Yug Rossii: ekologiya, i razvitie [South of Russia: Ecology, Development], 2018, no. 1, pp. 116-127.

13. Skolzneva L.N., Nedosekina T.V. Vliyanie pirogennogo faktora na rastitelnost Morozovoy gory [Influence of the Pyrogenic Factor on the Vegetation of the Moroz Mountain]. Flora i rastitelnost Tsentralnogo Chernozemiya - 2013 [Flora and Vegetation of the Central Chernozem'e- 2013: Materials of the Interreg. Sci. Confer.]. Kursk, 2013, pp. 141-146.

14. Shinkarenko S.S., Berdengalieva A.N. Analiz mnogoletney dinamiki stepnykh pozharov $\mathrm{v}$ Volgogradskoy oblasti [Analysis of Steppe Fires LongTerm Dynamics in Volgograd Region]. Sovremennye problemy distantsionnogo zondirovaniya Zemli iz kosmosa [Current problems in remote sensing of the Earth from space], 2019, vol. 16, no. 2, pp. 98-110.

15. Shinkarenko S.S. Identifikatsiya stepnykh pozharov po dannym Landsat i MODIS [Identification of Steppe Fires According to the Data of Landsat and MODIS]. Nauchno-Agronomicheskiy zhurnal [Agronomy Scientific Journal], 2017, no. 2, pp. 32-34.

16. Shinkarenko S.S. Otsenka dinamiki ploshchadey stepnykh pozharov v Astrakhanskoy oblasti [Assessment of Steppe Burning Dynamicsin
Astrakhan Region]. Sovremennye problemy distantsionnogo zondirovaniya Zemli iz kosmosa [Current Problems in Remote Sensing of the Earth from Space], 2018, vol.15, no. 1, pp. 138-146.

17. Shinkarenko S.S. Prostranstvennovremennoy analiz stepnykh pozharov v Prieltonye na osnove dannykh DZZ [The Spatial and Temporal Analysis of Steppe Fires in Lake Elton Area Bbased on RSD]. Vestnik Volgogradskogo gosudarstvennogo universiteta. Seriya 11: Estestvennye nauki [Science Journal of Volgograd State University. Natural Sciences]. 2015, no. 1, pp. 87-94. DOI: http://dx.doi.org/ 10.15688/jvolsu11.2015.1.9.

18. Cheney N., Gould J.S., Catchpole W.R. The Influence of Fuel, Weather and Fire Shape Variables on Fire Spread in Grasslands. International Journal of Wildland Fire, 1993, vol. 3 (1), pp. 31-44.

19. Cheney P., Sullivan A. Grassfires: Fuel, Weather and Fire Behaviour. CSIRO Publishing, 2008. 150 p.

20. Dunkan R.S, Dunkan V.E. Forest Succession and Distance from Forest Edge in an Afro-Tropical Grassland. Biotropica, 2000, vol. 32 (1), pp. 33-41.

21. Giglio L., Schroeder W., Justice C.O. The Collection 6 MODIS Active Fire Detection Algorithm and Fire Products. Remote Sensing of Environment, 2016, vol. 178, pp. 31-41.

22. McArthur A.G. Grassland Fire Danger Meter MkV. CSIRO Division of Forest Annual Report, 1976$1977.58 \mathrm{p}$.

23. Morvan D., Meradji S., Mell W. Numerical Study of the Interaction Between a Head Fire and a Backfire Propagating in Grassland. Fire Safety ScienceProceedings of the Tenth International Symposium, 2011,pp. 1415-1424.

24. Schroeder W., Oliva P., Giglio L. The New VIIRS 375m Active Fire Detection Data Product: Algorithm Description and Initial Assessment. Remote Sensing of Environment, 2014, no. 143, pp. 85-96.

25. Wooster M.J., Zhukov B., Oertel D. Fire Radiative Energy for Quantitative Study of Biomass Burning: Derivation from the BIRD Experimental Satellite and Comparison to MODIS Fire Products. Remote Sensing of Environment, 2003, vol. 86.1, pp. 83-107. 


\section{Information about the Authors}

Stanislav S. Shinkarenko, Candidate of Sciences (Agricultural), Senior Researcher, Federal Scientific Centre of Agroecology, Complex Melioration and Protective Afforestation of the Russian Academy of Sciences, prosp. Universitetskiy, 97, 400062 Volgograd, Russian Federation; Associate Professor, Department of Geography and Cartography, Volgograd State University, prosp. Universitetskiy, 100, 400062 Volgograd, Russian Federation, vnialmi@bk.ru, shinkarenko@volsu.ru.

Asel N. Berdengalieva, Student, Department of Geography and Cartography, Volgograd State University, prosp. Universitetskiy, 100, 400062 Volgograd, Russian Federation, Berdengalieva@mail.ru.

Valeriya V. Doroshenko, Student, Department of Geography and Cartography, Volgograd State University, prosp. Universitetskiy, 100, 400062 Volgograd, Russian Federation, Gm191-VolSU@yandex.ru.

Kseniya A. Oleynikova, Doctoral Student, Federal Scientific Centre of Agroecology, Complex Melioration and Protective Afforestation of the Russian Academy of Sciences, prosp. Universitetskiy, 97, 400062 Volgograd, Russian Federation, foreigner-13@mail.ru.

\section{Информация об авторах}

Станислав Сергеевич Шинкаренко, кандидат сельскохозяйственных наук, научный сотрудник Федерального научного центра агроэкологии, комплексных мелиораций и защитного лесоразведения Российской академии наук, просп. Университетский, 97, 400062 г. Волгоград, Российская Федерация; доцент кафедры географии и картографии, Волгоградский государственный университет, просп. Университетский, 100, 400062 г. Волгоград, Российская Федерация, vnialmi@bk.ru, shinkarenko@volsu.ru.

Асель Нурлановна Берденгалиева, студентка кафедры географии и картографии, Волгоградский государственный университет, просп. Университетский, 100, 400062 г. Волгоград, Российская Федерация, Berdengalieva@mail.ru.

Валерия Витальевна Дорошенко, студентка кафедры географии и картографии, Волгоградский государственный университет, просп. Университетский, 100, 400062 г. Волгоград, Российская Федерация, Gm191-VolSU@yandex.ru.

Ксения Александровна Олейникова, аспирант Федерального научного центра агроэкологии, комплексных мелиораций и защитного лесоразведения Российской академии наук, просп. Университетский, 97, 400062 г. Волгоград, Российская Федерация, foreigner-13@mail.ru. 